\title{
Analisis Rating Sentimen pada Video di Media Sosial Youtube Menggunakan STRUCT-SVM
}

\author{
Kadek Ary Budi Permana ${ }^{1}$, Made Sudarma ${ }^{2}$, Wayan Gede Ariastina ${ }^{3}$ \\ [Submission: 18-02-2019, Accepted:15-04-2019]
}

\begin{abstract}
Sentiment analysis on comments can be used to determine sentiment rating. The comments used are comments on Youtube. The type of video used is the official trailer video Indonesian movie. This paper contains steps to determine sentiment rating by notice the structure of comments. The structure of comments is needed because not all comments are relevant to the topic. Classes on comments are divided into seven classes including positive films, neutral films, negative films, positive not films, neutral not film, negative not film, and spam / off-topic. Comments that have a positive film or film negative class are used to determine sentiment rating. The number of likes in comments also determines the sentiment rating. Comment classification using STRUCT-SVM. The results of STRUCT-SVM show accuracy of $70 \%$ for linear kernels and $71 \%$ for RBF kernels.
\end{abstract}

Key Words- Sentiment Analysis, Rating Sentimen, STRUCTSVM, Linear Kernel, RBF Kernel, Youtube

Intisari-Analisis sentimen pada komentar dapat digunakan untuk menentukan rating sentimen. Komentar yang digunakan adalah komentar yang terdapat pada Youtube. Jenis video yang digunakan adalah video official trailer film Indonesia. Pada paper ini memuat tentang langkah-langkah dalam menentukan rating sentimen dengan memperhatikan struktur komentar. Pengenalan struktur komentar diperlukan karena tidak semua komentar relevan dengan topik yang bersangkutan. Kelas pada komentar dibagi menjadi tujuh kelas diantaranya positif film, netral film, negatif film, positif bukan film, netral bukan film, negatif bukan film, dan spam / diluar topik. Komentar dengan hasil klasifikasi positif film dan negatif film yang digunakan dalam menentukan rating sentimen. Jumlah like pada komentar juga ikut menentukan rating sentimen. Klasifikasi komentar menggunakan STRUCT-SVM. Hasil dari STRUCT-SVM menunjukkan akurasi mencapai $\mathbf{7 0 \%}$ untuk linear kernel dan $71 \%$ untuk RBF kernel.

Kata Kunci- Analisis Sentimen, Rating Sentimen, STRUCTSVM, Linear Kernel, RBF Kernel, Youtube

\section{PENDAHULUAN}

Media sosial menjadi tempat berbagi berbagai hal, diantaranya seperti berbagi berita, gambar, video, dan sebagainya. Salah satu hal yang menarik pada media sosial saat ini adalah bagaimana pengguna dapat memberikan suatu opini atau komentar pada suatu topik. Melakukan analisis terhadap komentar pengguna tentunya akan bermanfaat untuk

\footnotetext{
${ }^{1}$ Mahasiswa Pascarajana, Jurusan Teknik Elektro dan Komputer Fakultas Teknik Universitas Udayana, Jln. Jalan Kampus Bukit Jimbaran 80361 INDONESIA (telp: 0361-703315; fax: 0361-4321; e-mail: arybudi1@gmail.com)

2, 3 Dosen,Jurusan Teknik Elektro dan Komputer Fakultas Teknik Universitas Udayana, Jln. Jalan Kampus Bukit Jimbaran 80361 INDONESIA (telp: 0361-703315; fax: 0361-4321; e-mail: imasudarma@gmail.com ${ }^{2}$,w.ariastina@gmail.com ${ }^{3}$ )
}

Kadek Ary Budi Permana: Analisis Rating Sentimen pada ... mengetahui apakah penilaian yang terdapat pada komentar bersifat baik (positif) atau tidak baik (negatif) bahkan tidak keduanya (netral). Hasil dari analisis sentimen dapat dikembangkan untuk memberikan score atau rating terhadap suatu topik. Hal ini dapat diistilahkan sebagai rating sentimen. Rating sentimen merupakan persentase sentimen dari keseluruhan komentar. Rating sentimen ini juga dapat dijadikan sebagai pembanding antara penilaian pada suatu topik dengan topik lainnya.

Media sosial yang digunakan sebagai sumber data adalah media sosial Youtube. Youtube adalah salah satu sumber informasi video yang memiliki pengguna aktif terbesar, dimana pengguna dapat berinteraksi dengan berbagi video, memberikan like atau dislike, menambah viewer terhadap suatu video dan berlangganan (subscribe) pada suatu channel. YouTube juga memfasilitasi pengguna untuk menanggapi video dengan cara memberikan komentar. Terkadang video yang tidak relevan dan memiliki kualitas rendah berhasil menduduki peringkat yang lebih tinggi dalam hasil pencarian karena jumlah viewer atau like yang lebih banyak [1]. Dalam permasalahan tersebut, rating sentimen dapat dijadikan salah satu parameter untuk hasil pencarian atau rekomendasi video.

Teknik klasifikasi sentimen dapat digunakan untuk menentukan polaritas setiap komentar tunggal dan kemudian digabungkan menjadi rating sentimen [2]. Dalam melakukan analisis sentimen untuk menghasilkan rating sentimen memiliki permasalahan dimana tidak semua komentar relevan kepada topik yang bersangkutan [3]. Sehingga tidak semua komentar dapat dijadikan parameter dalam menentukan rating sentimen. Oleh karena itu, penelitian ini menambahkan pengenalan struktur komentar sebagai parameter dalam melakukan klasifikasi komentar. Jumlah like yang ada pada masing-masing komentar juga ikut dalam menentukan hasil dari rating sentimen. Jumlah like pada komentar dapat diasumsikan sebagai jumlah pengguna yang setuju pada komentar tersebut.

Penelitian ini menggunakan pendekatan struktural (STRUCT) dan menggunakan Support Vector Machine (SVM). Model STRUCT mengkodekan setiap komentar ke dalam shallow syntactic tree [4]. Pengunaan algoritma SVM untuk klasifikasi dapat bekerja lebih baik dengan dataset yang besar [5]. Penggunaan STRUCT-SVM diharapkan mampu mengklasifikasikan sentimen serta mengklasifikasikan apa yang dituju oleh komentar berdasarkan struktur komentar. Hasil dari klasifikasi sentimen dengan STRUCT-SVM ini yang menentukan rating sentimen

\section{STUDI LITERATUR}

\section{A. Analisis Sentimen}

Analisis sentimen atau bisa disebut juga opinion mining p-ISSN:1693 - 2951; e-ISSN: 2503-2372 
adalah riset komputasional dari opini, sentimen, dan emosi yang diekspresikan secara tekstual. Jika diberikan satu set dokumen teks yang berisi opini atau sentimen mengenai suatu objek, maka analisis sentimen betujuan untuk mengekstrak atribut dan komponen dari objek yang telah dikomentari pada setiap dokumen dan menentukan apakah komentar tersebut positif atau negatif [6].

Sentimen memiliki polaritas (positif atau negatif), sumber (orang atau kelompok orang yang memiliki sentimen), dan target (hal yang menjadi arah tujuan sentimen). Dalam teks, sentimen dapat ditangkap pada berbagai tingkatan diantaranya pada tingkat dokumen, paragraf, kalimat, atau klausa. Pada setiap tingkatan tertentu memiliki berbagai komponen sentimen (polaritas, sumber, dan target) yang berlaku dan berbagai teknik yang berbeda dapat digunakan untuk mengidentifikasi sentimen tersebut [7].

\section{B. Rating Sentimen}

Rating sentimen adalah salah satu metode yang digunakan untuk mengetahui tingkat sentiment terhadap suatu topik. Rating sentimen ditentukan oleh semua kelas yang terdapat pada setiap komentar yang terkait dengan topik. Metode yang digunakan pada penelitian ini untuk menghitung rating sentimen adalah weighted average [2]. Persamaan weighted average dapat dilihat pada persamaan (1).

$\operatorname{Score}_{W A v g}\left(m_{i}\right)=\frac{1}{n} \times \sum_{c \in m_{i}} \operatorname{Polatiry}(c) * \operatorname{Likes}(c)$

\section{STRUCT -SVM}

Klasifikasi $S V M$ dengan input $x$ dapat dihitung dengan persamaan (2). $a_{i}$ adalah parameter model yang diperkirakan dari data pelatihan, $y_{i}$ adalah variabel target yang merupakan daftar kelas yang sudah didefinisikan sebelumnya, $x_{i}$ adalah vektor pendukung yang berasal dari data yang direpresentasikan menjadi numerik atau vektor, dan $K$ adalah fungsi kernel.

$h(x)=\sum_{i} a_{i} y_{i} K\left(x, x_{i}\right)$

Shallow syntactic Tree Kernel (SHTK) digunakan untuk menangani rekayasa fitur atas representasi struktural dari model STRUCT. Dalam menggabungkan model STRUCT dan vektor maka memperlakukan setiap komentar dengan shallow syntactic tree $T$ dan vektor $v$ [4]. Oleh karena itu, untuk setiap pasangan komentar $x_{1}$ dan $x_{2}$ didefinisikan kernel seperti pada persamaan (3).

$K\left(x_{1}, x_{2}\right)=K_{T K}\left(T_{1}, T_{2}\right)+K_{v}\left(v_{1}, v_{2}\right)$

$K_{T K}$ adalah $S H T K$ dan $K_{v}$ adalah kernel vektor. Kernel vektor pada $S V M$ misalnya seperti linear kernel dan $R B F$ (Radial Basis Function) kernel. Persamaan kernel vektor dapat dilihat pada persamaan (4) dan (5).

Linear $K_{v}\left(v_{1}, v_{2}\right)=\left(v_{1} \cdot v_{2}\right)$

$R B F \quad K_{v}\left(v_{1}, v_{2}\right)=\exp \left(-\frac{\left\|v_{1}-v_{2}\right\|^{2}}{2 \sigma^{2}}\right)$

Untuk meningkatkan perhitungan kecepatan $T K$, maka dipertimbangkan pasangan node $\left(n_{l}, n_{2}\right)$ yang termasuk dalam tingkat pohon yang sama. Dengan demikian maka diberikan $H$ untuk ketinggian pohon STRUCT. $N_{T_{1}}^{h}$ dan $N_{T_{2}}^{h}$ adalah set node pada ketinggian $h$ [4]. Persamaan (6) mendefinisikan persamaan SHTK.

$\operatorname{SHTK}\left(T_{1} \cdot T_{2}\right)=\sum_{h=1}^{H} \sum_{n_{1} \in N_{T_{1}}^{h}} \sum_{n_{1} \in N_{T_{2}}^{h}} \Delta\left(n_{1}, n_{2}\right)$

Untuk mendapatkan nilai diantara 0 dan 1 , normalisasi SHTK dapat dilakukan dengan persamaan (7) [4].

$\frac{\operatorname{SHTK}\left(T_{1}, T_{2}\right)}{\sqrt{\operatorname{SHTK}\left(T_{1}, T_{1}\right) \times \operatorname{SHTK}\left(T_{2}, T_{2}\right)}}$

\section{Metode PENELITIAN}

Data komentar pengguna dikumpulkan dengan memanfaatkan API Youtube. Data yang digunakan adalah data komentar pada konten video official trailer. Pengelolaan data diawali dengan memberi label atau kelas pada komentar pengguna ke dalam tujuh kelas secara manual berdasarkan teori penelitian [8] untuk proses pelatihan. Kelas tersebut terdiri dari positif film, netral film, negatif film, positif bukan film, netral bukan film, negatif bukan film, dan komentar spam / di luar topik. Selanjutnya terdapat proses text preprocessing diantaranya tokenizing, case folding, stopword removal, stemming dan slangword fixing. Setelah proses text preprocessing selesai maka dilanjutkan dengan tahap feature extraction dimana terdapat empat fitur diantaranya $P O S$ Tagging dengan pendekatan STRUCT, negasi, TF dan TF-IDF.

Hasil klasifikasi dengan STRUCT-SVM digunakan sebagai dasar dalam perhitungan rating sentimen. Kelas yang digunakan dalam perhitungan rating sentimen adalah film positif dan film negatif serta mempertimbangkan jumlah like pada setiap komentar pada kedua kelas tersebut. Untuk mengetahui performa rating sentimen maka dilakukan pengujian dari klasifikasi yang dihasilkan. Pengujian dilakukan dengan menghitung recall, precision, f-measure, dan akurasi.

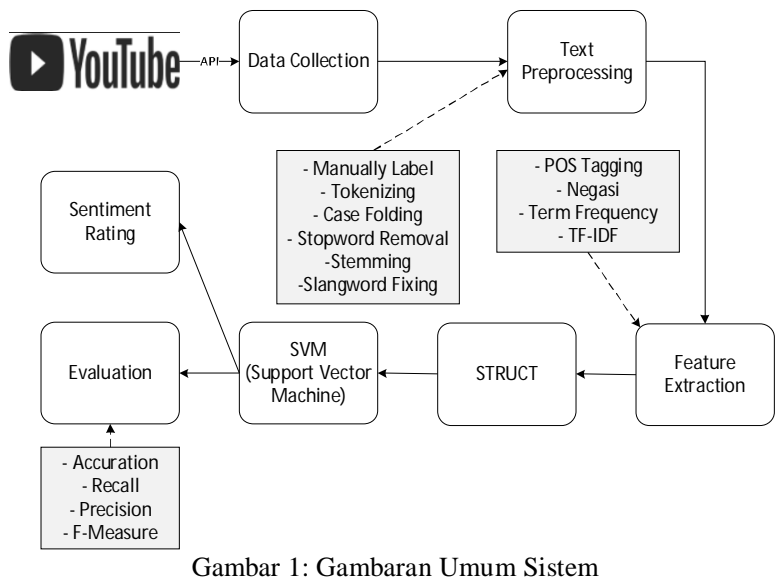

\section{A. Data}

Jenis video yang difokuskan pada penelitian ini adalah official trailer film Indonesia pada Youtube dan komentar dalam Bahasa Indonesia. Secara umum official trailer adalah istilah yang sering digunakan dalam dunia perfilman yang merujuk pada upaya promosi sebuah film yang akan segera tayang dengan bentuk video berdurasi singkat. Untuk contoh komentar dengan kelasnya masing-masing dapat dilihat pada tabel 1. 
TABEL I

CONTOH KOMENTAR DENGAN KELASNYA

\begin{tabular}{|l|c|}
\hline \multicolumn{1}{|c|}{ Komentar } & Kelas \\
\hline $\begin{array}{l}\text { Sumpah senyum2 sendiri. Ini novel dan film } \\
\text { romantis terhebat sepanjang masa. Mewakili } \\
\text { seluruh perasaan wanita dan perjuangan seorang } \\
\text { dilan untuk milea }\end{array}$ & Positif Film \\
\hline Film Keren tapi jelek & Netral Film \\
\hline $\begin{array}{l}\text { Film ni Gak Bener, gak mendidik sma sekali nii } \\
\text { film }\end{array}$ & $\begin{array}{c}\text { Negatif } \\
\text { Film }\end{array}$ \\
\hline Iqballl ganteng banget sihhh & $\begin{array}{c}\text { Positif } \\
\text { Bukan Film }\end{array}$ \\
\hline $\begin{array}{l}\text { Siapa yang tau film "REFRAIN" yg pemeran nya } \\
\text { afgan sama maudy ayunda... Sama kan ceritanya } \\
\text { hahaha }\end{array}$ & $\begin{array}{c}\text { Netral } \\
\text { Bukan Film }\end{array}$ \\
\hline $\begin{array}{l}\text { uh guru gblk, masa tkut ama muridnya } \\
\text { DONG00000 bat anyingggg }\end{array}$ & $\begin{array}{c}\text { Negatif } \\
\text { Bukan Film }\end{array}$ \\
\hline $\begin{array}{l}\text { mampir } \\
\text { guy's..https://www.wattpad.com/534934710- } \\
\text { rindu-sendiri }\end{array}$ & $\begin{array}{c}\text { Spam /di } \\
\text { luar topik }\end{array}$ \\
\hline
\end{tabular}

Penelitian ini menggunakan tiga film dengan total jumlah komentar 4199. Film tersebut terdiri dari Dilan 1990 (Film 1), Pengabdi Setan (Film 2), dan Warkop DKI Reborn : Jangkrik Boss Part 1 (Film 3). Komentar dibagi menjadi data train dan data test. Tabel 2 menunjukkan jumlah dari kedua data tersebut. Data train digunakan untuk melatih metode yang digunakan dalam melakukan klasifikasi sedangkan data test digunakan untuk menguji performa dan kebenaran dari hasil klasifikasi.

TABEL II

JUMLAH DATA TRAIN DAN DATA TEST

\begin{tabular}{|c|c|c|}
\hline Kelas & Train & Test \\
\hline Positif Film & 1098 & 753 \\
\hline Netral Film & 144 & 81 \\
\hline Negatif Film & 246 & 166 \\
\hline Positif Bukan Film & 320 & 207 \\
\hline Netral Bukan Film & 503 & 351 \\
\hline Negatif Bukan Film & 69 & 49 \\
\hline Spam / di luar topik & 130 & 81 \\
\hline Total & 2510 & 1689 \\
\hline
\end{tabular}

\section{B. Text Preprocessing}

Tahap text preprocessing diawali dengan pemecahan komentar menjadi beberapa token yang disebut tokenizing. Token yang dimaksud adalah per-kata. Kemudian dilakukan case folding atau merubah text menjadi lowercase/huruf kecil. Setelah itu stopword pada komentar dihilangkan dan semua kata yang memiliki imbuhan diubah ke dalam bentuk kata dasar yang dilakukan pada tahapan stemming. Stemming berhasil meningkatkan hasil akurasi namun tidak terlalu tinggi [9]. Setelah stemming, semua kata dibandingkan dengan kamus kata dasar Bahasa Indonesia yang dimiliki sistem. Jika terdapat kata yang tidak sesuai (slangword) dengan kamus, maka kata tersebut perlu didefinisikan sesuai dengan kata yang ada pada kamus. Slangword fixing dapat meningkatkan keakuratan klasifikasi dan memperkecil ukuran data [10]. Penggantian slangword digunakan untuk menghasilkan data yang masuk akal [11]. Setelah kata-kata slangword didefinisikan maka akan diperiksa kembali pada proses penghapusan stopword dan stemming. Jika masih terdapat kata slangword maka proses slangword fixing akan berulang kembali sedangkan jika tidak maka text preprocessing selesai.

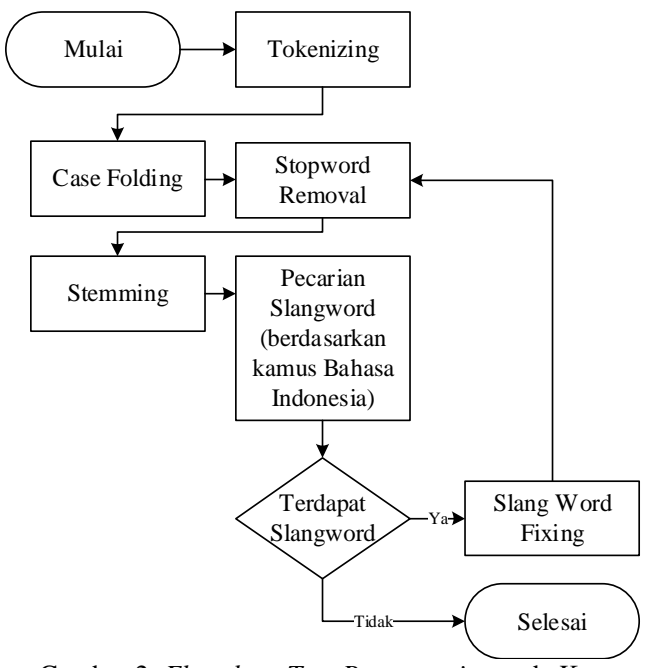

Gambar 2: Flowchart Text Proprocesing pada Komentar

\section{Pendekatan STRUCT}

Pengenalan struktur komentar digunakan pada penelitian ini untuk mengetahui apa yang dituju dari suatu komentar. Pengenalan struktur komentar dengan metode STRUCT dilakukan dengan memberikan tag pada kata-kata tertentu. Pemberian tag digunakan untuk membantu mengatasi kata yang tidak dapat didefinisikan atau kata ambigu [12]. Pendekatan pada penelitian ini menggunakan 3 tag diantaranya kata yang berhubungan dengan film ([FILM]), kata sentimen positif atau negatif ([POSITIF] atau [NEGATIF]), dan kata negasi seperti kata "tidak", "bukan", dan sebagainya ([NEGASI]).

Sebagai contoh pada komentar "dilan peran iqbal bagus tidak suka milea" menghasilkan struktur komentar yaitu "[FILM] [FILM[dilan]] [FILM] [FILM[peran]] [FILM] [FILM[iqbal]] [POSITIF] [POSITIF[bagus]] [NEGASI] [NEGASI[tidak]] [POSITIF] [POSITIF[suka] $\quad[$ FILM] [FILM[milea]]”.

\section{STRUCT-SVM dalam menentukan Rating Sentimen}

Hasil dari text preprocessing mengalami proses ekstraksi menggunakan $T F-I D F$ dan pengenalan struktur dengan pendekatan STRUCT. Hasil dari TF-IDF diproses lebih lanjut dengan linear kernel atau RBF kernel dan hasil dari STRUCT menggunakan SHTK. Gabungan kernel inilah yang mempengaruhi perhitunngan pada STRUCT-SVM. Hasil klasifikasi kemudian yang menentukkan rating sentimen. Gambaran dari proses STRUCT-SVM dalam menentukan rating sentimen dapat dilihat pada gambar 3 . 




Gambar 3: STRUCT-SVM dalam menentukan Rating Sentimen

\section{HASIL DAN PEMBAHASAN}

Hasil klasifikasi STRUCT-SVM menggunakan linear kernel dan RBF kernel. Tabel 3 menunjukkan komentar pada masing-masing kelas yang telah berhasil diklasifikasikan dengan menggunakan STRUCT-SVM dengan linear kernel.

TABEL III

HASIL KLASIFIKASI STRUCT-SVM DENGAN LINEAR KERNEL

\begin{tabular}{|c|c|c|c|}
\hline Kelas & Film 1 & Film 2 & Film 3 \\
\hline Positif Film & 177 & 396 & 393 \\
\hline Netral Film & 4 & 10 & 7 \\
\hline Negatif Film & 21 & 39 & 36 \\
\hline Positif Bukan Film & 12 & 17 & 37 \\
\hline Netral Bukan Film & 147 & 155 & 136 \\
\hline Negatif Bukan Film & 8 & 3 & 10 \\
\hline Spam / di luar topik & 33 & 31 & 17 \\
\hline Total & 402 & 651 & 636 \\
\hline
\end{tabular}

Untuk hasil dari perhitungan STRUCT-SVM dengan RBF kernel dapat dilihat pada tabel 4 . Tedapat beberapa perbedaan hasil klasifikasi antara STRUCT-SVM yang menggunakan linear kernel dan RBF Kernel.

TABEL IV

HASIL KLASIFIKASI STRUCT-SVM DENGAN RBF KERNEL

\begin{tabular}{|c|c|c|c|}
\hline Kelas & Film 1 & Film 2 & Film 3 \\
\hline Positif Film & 175 & 385 & 366 \\
\hline Netral Film & 4 & 16 & 5 \\
\hline Negatif Film & 22 & 43 & 51 \\
\hline Positif Bukan Film & 18 & 24 & 52 \\
\hline Netral Bukan Film & 142 & 149 & 133 \\
\hline Negatif Bukan Film & 8 & 3 & 12 \\
\hline Spam / di luar topik & 33 & 31 & 17 \\
\hline Total & 402 & 651 & 636 \\
\hline
\end{tabular}

Dalam menentukan rating sentimen menggunakan kelas yang berhubungan dengan film diantaranya positif film dan negatif film. Kelas netral film adalah kelas yang berhubungan dengan film tetapi memiliki polaritas 0 sehingga tidak diikutsertakan dalam menentukan rating sentimen. Komentar dengan kelas yang tidak berhubungan dengan film seperti positif bukan film, netral bukan film, negatif bukan film, dan spam juga tidak digunakan dalam menentukan rating sentimen. Hal ini sejalan dengan tujuan penggunaan STRUCT$S V M$ sebagai metode klasifikasi yang melakukan klasifikasi berdasarkan sentimen dan struktur komentar. Perhitungan rating sentimen atau score menggunakan persamaan (1) dimana komentar pada kelas film positif bernilai positif $(+1)$ dan film negatif bernilai negatif (-1). Jumlah like pada setiap komentar berarti setiap nilai komentar yang bernilai positif $(+1)$ ataupun negatif $(-1)$ dikalikan dengan jumlah like yang terdapat pada masing-masing komentar. Pada tabel 5 menunjukkan score dari setiap film pada kedua kernel.

TABEL V

SCORE PADA SETIAP FILM

\begin{tabular}{|c|c|c|c|c|c|c|c|}
\hline \multirow{2}{*}{ No } & Film & \multicolumn{3}{|c|}{ Linear Kernel } & \multicolumn{3}{c|}{ RBF Kernel } \\
\cline { 3 - 8 } & $\begin{array}{c}\text { Nilai } \\
\text { Positif } \\
\text { Film }\end{array}$ & $\begin{array}{c}\text { Nilai } \\
\text { Negatif } \\
\text { Film }\end{array}$ & Score & $\begin{array}{c}\text { Nilai } \\
\text { Positif } \\
\text { Film }\end{array}$ & $\begin{array}{c}\text { Nilai } \\
\text { Negatif } \\
\text { Film }\end{array}$ & Score \\
\hline 1 & Film 1 & 3422 & 37 & 0.98 & 3426 & 37 & 0.98 \\
\hline 2 & Film 2 & 338 & 37 & 0.80 & 334 & 39 & 0.79 \\
\hline 3 & Film 3 & 271 & 24 & 0.84 & 267 & 30 & 0.80 \\
\hline
\end{tabular}

Nilai positif film adalah jumlah dari seluruh komentar pada kelas positif film yang dikalikan dengan jumlah like pada masing-masing komentar. Nilai negatif film didapat dengan cara yang sama dengan nilai positif film tetapi menggunakan kelas yang berbeda yaitu kelas negatif film. Score didapat dari nilai positif film dikurang dengan nilai negatif film yang selanjutnya dibagi dengan jumlah dari nilai positif film dan nilai negatif film. Score memiliki nilai minimal -1 sampai dengan nilai maksimal +1 . Penelitian ini menggambarkan rating sentimen dengan nilai berbentuk bintang diantara 0 sampai dengan 5 maka nilai score tersebut perlu dikalikan 5 . Rating sentimen dapat bernilai negatif jika score bernilai negatif. Jika score bernilai negatif maka rating sentimen adalah 0 . Tampilan rating sentimen dapat dilihat pada gambar 4. Semakin besar rating sentimen menunjukkan komentar positif lebih mendominasi dari komentar negatif.

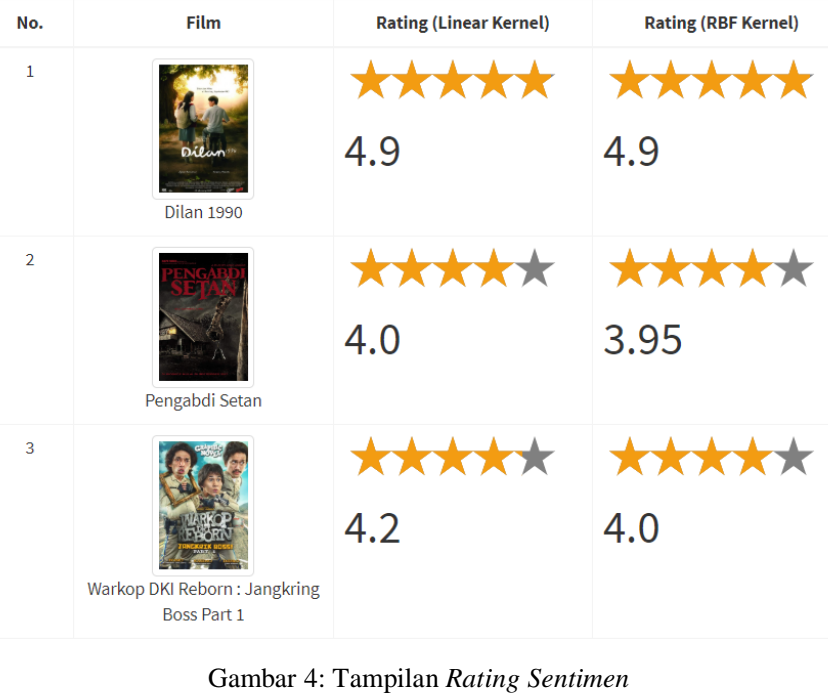

Gambar 4 menunjukkan beberapa perbedaan rating sentimen yang dihasilkan antara linear kernel dan RBF kernel pada masing-masing film. Perbedaan klasifikasi antara dua kernel tersebut tentunya yang mempengaruhi perbedaan rating sentimen. Untuk mengetahui kernel yang memiliki akurasi terbaik dalam menentukan rating sentimen maka perlu dilakukan pengujian terhadap hasil klasifikasi pada masingmasing kernel. Pada hasil klasifikasi dilakukan evaluasi pengujian menggunakan metode confusion matrix dengan membandingkan hasil klasifikasi (prediksi) dengan hasil 
sebenarnya. Metode ini dapat menentukan recall, precision, $f$ measure, dan akurasi. Pada tabel 6 menunjukkan nilai precision, recall, dan f-measure pada masing-masing kelas menggunakan STRUCT-SVM dengan linear kernel.

TABEL VI

HASIL PENGUJIAN STRUCT-SVM DENGAN LINEAR KERNEL

\begin{tabular}{|l|c|c|c|}
\hline \multicolumn{1}{|c|}{ Kelas } & Precision & Recall & F-Measure \\
\hline Positif Film & 0.72 & 0.89 & 0.8 \\
\hline Netral Film & 0.36 & 0.2 & 0.26 \\
\hline Negatif Film & 0.63 & 0.4 & 0.49 \\
\hline Positif Bukan Film & 0.56 & 0.29 & 0.38 \\
\hline Netral Bukan Film & 0.58 & 0.75 & 0.65 \\
\hline Negatif Bukan Film & 0.43 & 0.18 & 0.26 \\
\hline Spam & 0.74 & 0.32 & 0.44 \\
\hline
\end{tabular}

Dari hasil pengujian pada tabel 6 maka didapatkan rata-rata nilai precision $66 \%$, recall $50 \%$, dan $f$-measure $53 \%$. Nilai akurasi klasifikasi secara keseluruhan yaitu sebesar 70\%. Pada Tabel 7 menunjukkan nilai precision, recall, dan f-measure pada masing-masing kelas menggunakan STRUCT-SVM dengan RBF kernel .

TABEL VII

HASIL PENGUJIAN STRUCT-SVM DENGAN RBF KERNEL

\begin{tabular}{|l|c|c|c|}
\hline \multicolumn{1}{|c|}{ Kelas } & Precision & Recall & F- Measure \\
\hline Positif Film & 0.7 & 0.87 & 0.78 \\
\hline Netral Film & 0.46 & 0.25 & 0.32 \\
\hline Negatif Film & 0.58 & 0.44 & 0.5 \\
\hline Positif Bukan Film & 0.58 & 0.35 & 0.44 \\
\hline Netral Bukan Film & 0.57 & 0.75 & 0.65 \\
\hline Negatif Bukan Film & 0.48 & 0.19 & 0.27 \\
\hline Spam & 0.76 & 0.32 & 0.45 \\
\hline
\end{tabular}

Berbeda dengan hasil menggunakan linear kernel, $R B F$ kernel menghasilkan hasil yang lebih baik. Ini dapat dilihat dari hasil pengujian pada tabel 7 dimana didapatkan rata-rata nilai precision $67 \%$, recall $53 \%$, dan $f$-measure $56 \%$. Nilai akurasi klasifikasi secara keseluruhan yaitu sebesar $71 \%$. Pada gambar 5 dapat dilihat grafik dari nilai rata-rata precision, recall, f-maeasure, dan akurasi dari STRUCT-SVM dengan linear kernel maupun RBF kernel.

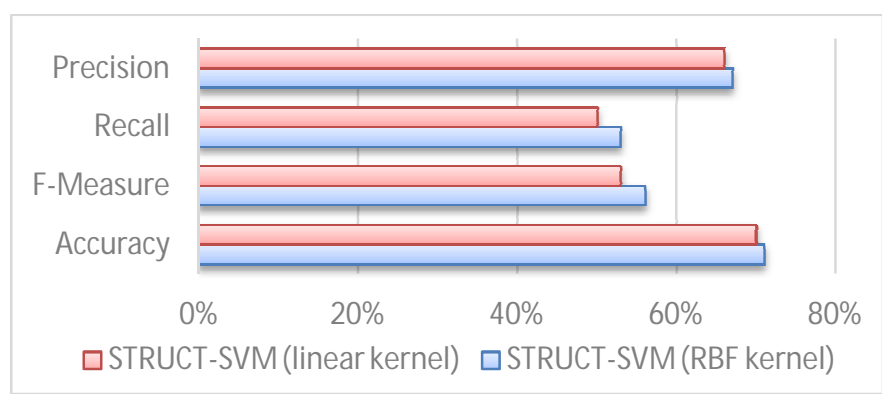

Gambar 5: Grafik Pengujian STRUCT-SVM (linear kernel dan RBF kernel)
Grafik menunjukkan STRUCT-SVM dengan RBF kernel memiliki hasil klasifikasi yang lebih baik dari linear kernel. Hal ini juga menunjukkan rating sentimen dengan menggunakan hasil klasifikasi dari STRUCT-SVM dengan RBF kernel memiliki performa yang lebih baik.

\section{KESIMPULAN}

STRUCT-SVM berhasil melakukan klasifikasi dengan mempertimbangkan sentimen dan struktur komentar. Rating sentimen berhasil didapatkan dari hasil klasifikasi tersebut dan memanfaatkan jumlah like pada setiap komentar di kelas yang berhubungan dengan film. Nilai rata-rata dari STRUCT-SVM dengan linear kernel adalah precision $66 \%$, recall $50 \%, f$ measure 53\%, dan akurasi sebesar $70 \%$. Sedangkan untuk nilai rata-rata STRUCT-SVM dengan RBF kernel adalah precision $67 \%$, recall $53 \%$, dan $f$-measure $56 \%$ dan akurasi sebesar $71 \%$. Nilai dari pengujian menunjukkan bahwa STRUCT-SVM dengan RBF kernel lebih baik daripada linear kernel dalam melakukan klasifikasi dan menentukkan rating sentimen.

Selain memperhatikan struktur komentar dalam menentukkan rating sentimen, hal lain juga dapat dikembangkan untuk lebih baik lagi yaitu dengan penggunaan sinonim kata. Penggunaan sinonim kata dapat memperkecil ukuran data pada proses klasifkasi. Misalnya kata "apik", "bagus", dan "keren" dapat dijadikan satu kata yaitu "baik".

\section{REFERENSI}

[1] H. Bhuiyan, J. Ara, R. Bardhan, and M. R. Islam, "Retrieving YouTube video by sentiment analysis on user comment," Proc. 2017 IEEE Int. Conf. Signal Image Process. Appl. ICSIPA 2017, no. 1, pp. 474-478, 2017.

[2] J. H. Wang and T. W. Liu, "Improving sentiment rating of movie review comments for recommendation," 2017 IEEE Int. Conf. Consum. Electron. - Taiwan, ICCE-TW 2017, pp. 433-434, 2017.

[3] E. Rinaldi and A. Musdholifah, "FVEC-SVM for Opinion Mining on Indonesian Comments of YouTube Video," 2017.

[4] A. Severyn, A. Moschitti, O. Uryupina, B. Plank, and K. Filippova, "Opinion Mining on YouTube," pp. 1252-1261, 2014.

[5] S. Anastasia and I. Budi, "Twitter sentiment analysis of online transportation service providers," 2016 Int. Conf. Adv. Comput. Sci. Inf. Syst., pp. 359-365, 2016.

[6] B. Liu, "Sentiment Analysis and Subjectivity," pp. 1-38, 2010.

[7] C. R. Fink, D. S. Chou, J. J. Kopecky, and A. J. Llorens, "Coarseand fine-grained sentiment analysis of social media text," Johns Hopkins APL Tech. Dig. (Applied Phys. Lab., vol. 30, no. 1, pp. 2230, 2011.

[8] O. Uryupina, B. Plank, A. Severyn, A. Rotondi, and A. Moschitti, "SenTube: A corpus for sentiment analysis on YouTube social media," Proc. Lang. Resour. Eval. Conf., vol. 2, pp. 4244-4249, 2014.

[9] A. F. Hidayatullah, "The Influence of Stemming on Indonesian Tweet Sentiment Analysis," no. August, pp. 19-20, 2015.

[10] T. Singh and M. Kumari, "Role of Text Pre-Processing in Twitter Sentiment Analysis," Procedia - Procedia Comput. Sci., vol. 89, pp. 549-554, 2016.

[11] S. Gharatkar, A. Ingle, T. Naik, and A. Save, "Review Preprocessing Using Data Cleaning And Stemming Technique," Int. Conf. Innov. Inf. Embed. Commun. Syst. Rev., 2017.

[12] L. Kumar and P. K. Bhatia, "Text mining: concepts, process and applications," J. Glob. Res. Comput. Sci., vol. 4, no. 3, pp. 36-39, 2013. 
[Halaman ini sengaja dikosongkan] 